\title{
Large Eddy Simulation of Turbulent Rayleigh-Bénard Convection: An Assessment of Subgrid-Scale Models
}

\author{
Illyas YILMAZ \\ istanbul Bilgi University, Faculty of Engineering and Natural Sciences, Department of Mechanical Engineering, istanbul.
} e-posta: ilyas.yilmaz@bilgi.edu.tr.ORCID ID: https://orcid.org/0000-0003-2900-3080

Geliş Tarihi: 08.01.2021 Kabul Tarihi: 18.04.2021

\footnotetext{
Keywords

Computational Fluid Dynamics; Turbulence modeling; Large eddy simulation; Subgridscale model; RayleighBénard convection; Turbulent convection
}

\begin{abstract}
Large eddy simulation of turbulent Rayleigh-Bénard convection was carried out to assess various algebraic eddy viscosity subgrid-scale models: (i) Smagorinsky with Wall-Damping, (ii) Dynamic Smagorinsky, (iii) Wall-Adapting Local Eddy-Viscosity, (iv) Vreman, (v) Mixed-Scale, and (vi) a buoyancymodified Mixed-Scale model that accounts for the buoyancy effects from subgrid-scales. The last model is proposed for the first time in this study. Non-dissipative, kinetic energy conserving, fully implicit method was employed for simulations. To evaluate the models, mean and turbulent (both low- and high-order) flow diagnostics were computed. Some advanced turbulent statistics such as skewness, turbulent heat flux, subgrid-scale kinetic energy and Nusselt number were also calculated and compared with each other and against a reference solution. Since models differ from each other by means of turbulent generation terms, they have their own strengths and weaknesses which are particularly observed in the near-wall treatments. Additionally, unlike the others, the Dynamic Smagorinsky model computes the subgrid-scale viscosity coefficient dynamically which has some effects on results. Overall, the Mixed-Scale and its new, buoyancy-modified variant show different characteristics and mostly the best agreement with Direct Numerical Simulation data. They are also found computationally less expensive. Moreover, buoyancy enhancement in the new model slightly improves the predictions of Mixed-Scale model. Although relatively poor performance by the Dynamic Smagorinsky model is observed especially in estimating the integrated Nusselt number, it captures the turbulent heat flux more accurately than the others. A more detailed discussion on the model's performance based on evaluations are also made.
\end{abstract}

\section{Türbülanslı Rayleigh-Bénard Taşınım Probleminin Büyük Girdap Benzetimi: Ağaltı-ölçek Modellerinin Değerlendirilmesi}

Öz

Bu çalışmada türbülansı Rayleigh-Bénard ısıl taşınım problemi büyük girdap benzetimi metodu ile 6 farklı ağaltı-ölçek modeli kullanılarak gerçekleştirilmiştir. Bu modeller; (i) Smagorinsky (duvar sönümleme fonksiyonu da içeren), (ii) Dinamik Smagorinsky, (iii) Wall-Adapting Local Eddy-Viscosity, (iv) Vreman, (v) Mixed-Scale, ve (vi) ilk defa bu çalışmada önerilen ve ağaltı ölçeklerden gelen türbülanslı kaldırma kuvveti etkilerini de içerecek şekilde, terimleri yeniden düzenlenmiş ve zenginleştirilmiş olan değiştirilmiş-Mixed-Scale modelidir. Benzetimlerde sönümleme içermeyen, kinetik enerjiyi koruyan ve zamanda tamamıyla kapalı bir sayısal ayrıklaştırma algoritması kullanılmıştır. Modellerin değerlendirilmesi için, akışın ortalama ve türbülanslı büyüklükleri (hem düşük hem de yüksek mertebeli) hesaplanmıştır. Ayrıca, asimetri, türbülanslı ISı akısı, ağaltı-ölçek kinetik enerjisi ve Nusselt sayısı gibi ilave pek çok ileri seviye, türetilmiş türbülans parametresi de hesaplanmış ve karşılaştırmalarda kullanılmıştır. Bunlara ilişkin detaylı analizlere bu kapsamlı çalışmada yer verilmiştir. Elde edilen sonuçlar, her modelin zayıf ve güçlü yanlarını ortaya çıkarmıştır. Modeller arası farklııkların özellikle duvara yakın bölgelerde kendini gösterdiği ortaya konmuştur. Genel olarak, Mixed-Scale ve ona dayalı olarak önerilen yeni modelin performanslarının, Doğrudan Sayısal Benzetim metodu ile daha iyi bir uyum içerisinde olduğu gözlemlenmiştir. Bu iki model ayrıca daha kısa sürede sonuç vermesi sebebiyle de sayısal hesaplama maliyeti açısından avantajıdır. Kaldırma kuvveti etkilerini de içeren yeni modele ait sonuçlarının asıl modele oranla görece bir iyileşme içerdiği de görülmektedir. 


\section{Introduction}

Turbulent flows are characterized by rotational flow structures, so-called eddies, which have a broad range of length and time scales (Pope 2000). Larger eddies show highly anisotropic behavior and carry most of the energy. However, smaller ones are more isotropic and less energy-carrying. Large Eddy Simulation (LES) is based on this observation. Unlike the Direct Numerical Simulation (DNS) which tries to resolve all the scales by very fine grid sizes, LES filters out the smaller scales and resolves only the larger ones (Sagaut 2001). This is done by applying a filtering function. To separate the scales, the filtering function uses a cut-off length scale. Contributions which come from the remaining unresolved scales are modelled in LES. Top-hot or Box filter are widely utilized as filtering functions. It is also very common to take grid size as the cut-off length. Due to this choice, unresolved scales are frequently termed as subgrid-scales (sgs).

Eddy viscosity or turbulent viscosity is one of the most employed approaches used to model to sgs effects based on Boussinesq hypothesis. Unresolved scale contributions which arise as extra stress terms in the filtered momentum equations are taken proportional to the resolved strain rate with a sgs viscosity coefficient. A similar procedure, which is described as eddy diffusivity, is also used in the filtered energy equation to model the unresolved temperature field. Then, modeling is simply reduced to a problem of determining the sgs viscosity which can be done in various ways.

Among the sgs models, zero-equation (ie., algebraic) ones provide an efficient way to compute sgs viscosity. Various approaches have been proposed beginning from the 60's. The first model was developed by Smagorinsky (1963). Smagorinsky model was then reformulated to compute sgs viscosity dynamically (Yang and Ferziger 1993). Other widely used examples are the Wall-Adapting Local Eddy-Viscosity (WALE) model developed by Nicoud and Ducros (1999), Mixed-Scale model by Sagaut (1996) and a sgs model by Vreman (2004). It is possible to further extend the list. The main differences rely on calculating the turbulent generation term. It is an advanced differential operator which controls the contribution of sgs effects and mainly based on the various tensor fields formed by the velocity gradients. Some further details on the models are also provided in Sec. 2.

Turbulent thermal convection is a very challenging problem and characterized by complex physical interactions (Getling 1998). To properly simulate it using LES, a model which is capable of turbulent generation due buoyancy effects is required. The first attempt to develop such a model was made by Eidson (1985). Eidson enhanced the turbulent generation term due shear in Smagorinsky model by adding a buoyancy production. Peng and Davidson (1998) further reformulated his model to obtain a proper time scaling behavior that prevents possible non-physical solutions. A buoyancy-adjusted stretched-vortex sgs model was recently proposed by Chung and Matheou (2014) as an all-in-one model. Some other attempts on the sgs modeling of turbulent buoyant flows were also made. For a review, please refer to Peng and Davidson (1998) and Chung and Matheou (2014). In fact, this is still an active research area. Some of the more recent efforts can also be found, for instance, in Dabbagh et al. (2016) and Ranjan et al. (2020).

The main aim of this study is to evaluate the predicting capabilities of the above-mentioned algebraic sgs models in LES modeling of turbulent Rayleigh-Bénard convection (RBC). By doing so, subgrid-scale algebraic model benchmarking on a specific case is performed. Proposing an algebraic model, in the context of this work, is further aimed to improve the estimations. To achieve this goal, the terms of the Mixed-Scale model is reformulated to recognize the unstable thermal stratification, and by this way to better capture the unresolved thermal effects which enhance turbulence.

The remaining part of the manuscript is organized as follows. Numerical methodology including the LES equations, sgs models, solution algorithm and solver 
details are given in Sec. 2. Problem description and numerical setup are described in Sec. 3. Results are presented and comprehensively discussed in Sec. 4. Finally, conclusions are made in Sec. 5.

\section{Numerical Methodology}

\subsection{LES equations}

The non-dimensional, Favre-filtered LES equations with gravity read

$$
\begin{aligned}
& \frac{\partial \bar{\rho}}{\partial \mathrm{t}}+\frac{\partial\left(\bar{\rho} \tilde{u}_{j}\right)}{\partial x_{j}}=0 \\
& \frac{\partial\left(\bar{\rho} \tilde{u}_{i}\right)}{\partial t}+\frac{\partial\left(\bar{\rho} \tilde{u}_{i} \tilde{u}_{j}\right)}{\partial x_{j}} \\
& =-\frac{\partial \bar{p}}{\partial x_{i}}+\frac{1}{R e} \frac{\partial \bar{\tau}_{i j}}{\partial x_{j}} \\
& +\frac{\partial \tau_{i j}^{s g s}}{\partial x_{j}}+\frac{1}{F r^{2}} \bar{\rho} g_{i} \\
& M_{r}^{2}\left[\frac{\partial}{\partial t}\left(\bar{p}+(\gamma-1)\left(\frac{1}{2} \bar{\rho} \tilde{u}_{i} \tilde{u}_{i}\right)\right)\right. \\
& +\frac{\partial}{\partial x_{j}}(\gamma \bar{p} \\
& +(\gamma \\
& \text {-1) } \left.\left.\left(\frac{1}{2} \bar{\rho} \tilde{u}_{i} \tilde{u}_{i}\right)\right) \tilde{u}_{j}\right] \\
& +\frac{\partial \tilde{u}_{j}}{\partial x_{j}} \\
& =(\gamma \\
& \text {-1) } M_{r}^{2}\left[\frac{1}{R e} \frac{\partial\left(\tilde{\tau}_{i j} \tilde{u}_{i}\right)}{\partial x_{j}}\right. \\
& \left.+\frac{\partial\left(\tau_{i j}^{s g s} \tilde{u}_{i}\right)}{\partial x_{j}}\right] \\
& +\frac{\partial}{\partial x_{j}}\left(\frac{\mu}{\operatorname{RePr}} \frac{\partial \tilde{T}}{\partial x_{j}}\right. \\
& \left.-q_{i j}^{s g s}\right)+\frac{E c}{F r^{2}}\left(\bar{\rho} \tilde{u}_{i} g_{i}\right)
\end{aligned}
$$

where $x_{j}, t, \rho, g$ and $u_{i}$ denote $j^{\text {th }}$ co-ordinate direction, time, density, gravity, and velocity in the $x_{i}$ direction, respectively (Yilmaz et al. 2018). $\left(^{-}\right)$ and $\left(^{\sim}\right)$ are also used to represent the filtered and Favre-filtered variables. Additionally, $M_{r}, E c, R e$ and $\mathrm{Fr}$ are the Mach (reference), Eckert, Reynolds, and Froude numbers in their usual meanings, respectively.

In the above set of equations, $\tau_{i j}^{s g s}$ and $q_{j}^{s g s}$ represent the sgs stress tensor and the sgs heat flux term, respectively. $\tau_{i j}^{s g s}$ is modeled using the eddyviscosity assumption in which it is related to the resolved strain rate via the sgs dynamic viscosity, $\mu_{s g s}$, as

$$
\tau_{i j}^{s g s}=\mu_{s g s}\left(2 \tilde{S}_{i j}-\frac{2}{3} \frac{\partial \tilde{u}_{k}}{\partial x_{k}} \delta_{i j}\right)
$$

$\mu_{s g s}$ is further modeled via a sgs model which will be presented in the following subsection.

The sgs heat flux term is also modeled using the gradient approximation (also known as the eddydiffusivity hypothesis) as

$$
q_{j}^{s g s}=-\frac{\mu_{s g s}}{P r_{s g s}} \frac{\partial \tilde{T}}{\partial x_{j}}
$$

where $P r_{s g s}$ is the sgs Prandtl number usually taken as 0.8 .

Then, the final form of the Favre-filtered, nondimensional momentum and energy equations become

$$
\begin{aligned}
\frac{\partial\left(\bar{\rho} \tilde{u}_{i}\right)}{\partial \mathrm{t}}+\frac{\partial\left(\bar{\rho} \tilde{u}_{i} \tilde{u}_{j}\right)}{\partial x_{j}} & \\
& =-\frac{\partial \bar{p}}{\partial x_{i}} \\
& +\frac{\partial}{\partial x_{j}}\left[\left(\frac{\mu}{R e}\right.\right. \\
& \left.+\mu_{s g s}\right)\left(2 \tilde{S}_{i j}\right. \\
& \left.\left.-\frac{2}{3} \frac{\partial \tilde{u}_{k}}{\partial x_{k}} \delta_{i j}\right)\right]+\frac{1}{F r^{2}} \bar{\rho} g_{i}
\end{aligned}
$$

and 


$$
\begin{aligned}
M_{r}^{2}\left[\frac{\partial}{\partial t}(\bar{p}+(\gamma\right. & \left.-1)\left(\frac{1}{2} \bar{\rho} \tilde{u}_{i} \tilde{u}_{i}\right)\right) \\
& +\frac{\partial}{\partial x_{j}}(\gamma \bar{p} \\
& +(\gamma \\
& \left.\left.-1)\left(\frac{1}{2} \bar{\rho} \tilde{u}_{i} \tilde{u}_{i}\right)\right) \tilde{u}_{j}\right] \\
& +\frac{\partial \tilde{u}_{j}}{\partial x_{j}} \\
& =(\gamma \\
& -1) M_{r}^{2} \frac{\partial}{\partial x_{j}}\left[\left(\frac{\mu}{R e}\right.\right. \\
& \left.+\mu_{s g s}\right)\left(2 \tilde{S}_{i j}\right. \\
& \left.\left.-\frac{2}{3} \frac{\partial \tilde{u}_{k}}{\partial x_{k}} \delta_{i j}\right) \tilde{u}_{i}\right] \\
& +\frac{\partial}{\partial x_{j}}\left[\left(\frac{\mu}{R e P r}\right.\right. \\
& \left.\left.+\frac{\mu_{s g s}}{P r_{s g s}}\right) \frac{\partial \tilde{T}}{\partial x_{j}}\right] \\
& +\frac{E c}{F r^{2}}\left(\bar{\rho} \tilde{u}_{i} g_{i}\right)
\end{aligned}
$$

respectively. Finally, the equation of state is also introduced in its Favre-filtered, non-dimensional form as

$$
\bar{\rho} \tilde{T}=\gamma M_{r}^{2} \bar{p}+1
$$

\subsection{Subgrid-scale models}

Now, problem reduces to modeling $\mu_{s g s}$. Algebraic (zero-equation) eddy viscosity sgs models are considered in this study.

In the Smagorinsky model, $\mu_{s g s}$ is obtained via

$$
\mu_{s g s}=\bar{\rho}\left(C_{s} l_{m}\right)^{2}|\bar{S}|
$$

where $|\bar{S}|=\sqrt{2 \bar{S}_{i j} \bar{S}_{i j}}$ is the magnitude of the strain-rate tensor. $l_{m}$ is the the characteristic length scale of the resolved eddies set to grid spacing $\Delta=$ (volume $)^{\frac{1}{3}}$. The Smagorinsky constant, $C_{S}$, is taken as 0.1 . To improve the model's behavior near wall regions, $l_{m}$ should be adjusted by a wall model or a function. In the wall-damping Smagorinsky model (hereafter SmaWD) $l_{m}$ reads

$$
l_{m}=\min \left(C_{s} * \Delta, k_{v} * d_{w}\right)
$$

where $k_{v}$ is the von Karman constant set to 0.41 and $d_{w}$ is the normal distance to the nearest wall.

The dynamic Smagorinsky model (hereafter DynSma) implemented here is the one proposed by Yang and Ferziger (1993). It uses the same analogy as Smagorinsky model. However, $C_{s}$ is determined dynamically using a test filter as

$$
C_{s}=\frac{1}{2}=\frac{D_{i j} P_{i j}}{P_{i j} P_{i j}}
$$

Here,

$$
\begin{aligned}
& D_{i j}=T_{i j}-\tilde{\tau}_{i j} \\
& T_{i j}-\frac{\delta_{i j}}{3} T_{k k}=-2 C_{S}^{2} \widetilde{\Delta}^{2}|\tilde{\bar{S}}| \tilde{\bar{S}}_{i j}
\end{aligned}
$$

$$
P_{i j}=\Delta^{2}\left|\overline{\bar{S} \mid \bar{S}_{l \jmath}}-\widetilde{\Delta}^{2}\right| \tilde{\bar{S}} \mid \tilde{\bar{S}}_{i j}
$$

where $\left({ }^{\sim}\right)$ denotes the test filter which is taken as twice the grid filter and $T_{i j}$ is the sgs stresses on the test filter. This model allows back-scattering, i.e., negative $C_{s}$, from the small scales to the resolved flow and mostly needs numerical clipping to stabilize the solution.

WALE model employs the traceless symmetric part of the square of the velocity gradient tensor which reads

$$
S_{i j}^{d}=\frac{1}{2}\left(\bar{g}_{i j}^{2}+\bar{g}_{j i}^{2}\right)-\frac{1}{3} \delta_{i j} \bar{g}_{k k}^{2}
$$

and calculates $\mu_{s g s}$ using 


$$
\begin{aligned}
& \mu_{\text {sgs }} \\
& =\bar{\rho}\left(C_{w} \Delta\right)^{2} \frac{\left(S_{i j}^{d} S_{i j}^{d}\right)^{3 / 2}}{\left(\bar{S}_{i j} \bar{S}_{i j}\right)^{5 / 2}+\left(S_{i j}^{d} S_{i j}^{d}\right)^{5 / 4}}
\end{aligned}
$$

with $C_{w}=0.33$.

Vreman model is also an eddy-viscosity model that has the following algebraic relation

$$
\mu_{s g s}=\bar{\rho} C_{v} \sqrt{\frac{B_{\beta}}{\alpha_{i j} \alpha_{i j}}}
$$

with

$$
\begin{aligned}
& C_{v}=2.5 C_{s}^{2} \\
& \begin{aligned}
B_{\beta}= & \beta_{11} \beta_{12}- \\
& \beta_{12}^{2}+\beta_{11} \beta_{33}-\beta_{13}^{2} \\
& +\beta_{22} \beta_{33}-\beta_{23}^{2}
\end{aligned} \\
& \beta_{i j}=\Delta_{m}^{2} \alpha_{m i} \alpha_{m j} \\
& \alpha_{i j}=\frac{\partial \bar{u}_{j}}{\partial x_{i}}
\end{aligned}
$$

Another model introduced here is the Mixed-scale model (hereafter MS) by Sagaut (1996) as

$$
\mu_{s g s}=\bar{\rho} C_{m} \Delta^{1+\alpha}|\bar{S}| q^{(1-\alpha) / 2}
$$

where $C_{m}$ is the model constant computed as $C_{q}^{1-\alpha} C_{s}^{2 \alpha}$. $\quad C_{q}$ and $C_{s}$ are 0.9 and 0.17 , respectively. $q$ is the kinetic energy of the resolved fluctuations. An explicit second filter width of $\widehat{\Delta}=$ $2 \Delta$ is applied to the cut-off length scale to compute $q$. It is then found from

$$
q=\frac{1}{2}\left(\bar{u}_{\imath}-\hat{\bar{u}}_{i}\right)\left(\bar{u}_{\imath}-\hat{\bar{u}}_{i}\right)
$$

The parameter $\alpha$ controls the relative strength of small and large scales. It is typically set to 0.5 . For $\alpha=0$ model gives $\mu_{s g s}=\bar{\rho}\left(C_{m} \Delta\right) q^{1 / 2}$. On the other end, Smagorinsky model without wall- damping is obtained with $\alpha=1$ and finally the model becomes independent of the cut-off length $\Delta$, if $\alpha=-1$ is used.

Lastly, a novel buoyancy-modified sgs model is also proposed based on the MS to account for the buoyancy effects in unstably stratified thermal flows in which buoyancy enhances turbulence. The new buoyancy-modified MS (BM-MS) model computes $\mu_{\text {sgs }}$ using

$$
\begin{aligned}
& \mu_{s g s} \\
& =\bar{\rho} C_{m} \Delta^{1+\alpha}\left(|\bar{S}|^{2}\right. \\
& \left.-\frac{1}{F r^{2} P r_{s g s}} \frac{\partial \tilde{T}}{\partial x_{j}} \delta_{2 j}\right)^{1 / 2} q^{(1-\alpha) / 2}
\end{aligned}
$$

This formulation was obtained via enhancing the shear production of turbulent by buoyancy, following the ideas of Eidson (1985). The model reverts to the original MS for thermally unstratified flows.

\subsection{Solution algorithm}

Recently proposed, co-located, non-dissipative, fully implicit, kinetic energy conserving, finite-volume, LES algorithm is employed to solve the above set of equations (Yilmaz et al. 2018). The algorithm is the extended version of the DNS algorithm by Hou and Mahesh (2005) to LES. It is based on a low-Mach number, compressible formulation with variable density and dynamic viscosity. It is an iterative predictor-corrector approach based on pressurecorrection. It is second-order accurate in both space and time on uniform Cartesian grids. Thermodynamic variables are also staggered in time from kinematic variables. The face-normal velocity is treated as a separate flow variable and computed using projection. A weighted pressure variable is used for fully implicit treatment. A convergence speed-up procedure is also implemented. Further details of the algorithm and solution procedure can be found in the above references. 


\subsection{Flow Solver}

The in-house LES solver used in this study employs the numerical method described above. It is a fully implicit solver. It is completely written and parallelized with the object-oriented parallel programming library, the Portable, Extensible Toolkit for Scientific computation (PETSc), developed by Balay et al. (1997).

Domain decomposition and parallel data management are handled by the Distributed Array (DA) structure in PETSc. Linear systems arising from the fully implicit discretization are first preconditioned by zero-filled incomplete-LowerUpper (iLU) method, then efficiently solved by the Generalized Minimal Residual method (GMRES) provided by the Krylov Subspace (KSP) component in PETSc.

Models given in Sec. 2 were carefully implemented into this in-house solver.

\section{Problem Description and Numerical Setup}

RBC occurs when a horizontal layer of fluid between plates is heated from below and cooled from above (Getling 1998). It is an example of buoyancy-driven instability and plays an important role in many natural and industrial flows. Astrophysical flows (such as solar interiors), atmospheric flows, cooling flows (in nuclear reactors), fire, combustion and geophysical flows can be given as examples.

The Rayleigh number is the primary dimensionless quantity defined as

$$
R a=\frac{\rho g \beta \Delta T H^{3}}{\mu \kappa}
$$

where $\mathrm{K}$ is the thermal diffusivity coefficient. $R a$ indicates the relative strength of the heat transfer modes and controls the flow evolution. Also, it determines the character of the convective turbulence at later times (weak or strong). The temperature difference $\Delta T$ is set to $30 \mathrm{~K}$. Note that this is a large value and corresponds to the beginning of the non-Oberbeck-Boussinesq (OB) regime described by Gray and Giorgini (1976) which cannot be properly handled by the numerical methods that rely on $\mathrm{OB}$ assumption. However, the present method is $R a$ is set to $6.3 \times 10^{5}$. This corresponds to a relatively weak (soft) turbulent convection. Air is chosen as working fluid. The flow field is initially described as follows

$$
\begin{aligned}
& u, v, w=0 \\
& \rho=\rho_{0}\left(1+\beta\left(\frac{\Delta T}{H}\right) y\right) \\
& p=p_{0}-\rho g y \\
& T=T_{0}-\left(\frac{\Delta T}{H}\right) y
\end{aligned}
$$

$H$ is the extent of the domain and taken as the reference length. $u_{c}=\sqrt{g \beta \Delta T H}$ is the convective velocity scale. $\tau_{c}=\frac{H}{u_{c}}$ is the convective time scales. Horizontal (stream-wise $(x)$ and the span-wise $(z)$ boundary conditions are periodic. Top and bottom boundaries are no-slip walls.

The ratio of the width to the height of the domain is 4. The grid resolution is $64 \times 96 \times 64$. The smallest length scale (usually attributed to Kolmogorov) can be predicted as

$$
\frac{\eta}{H}=\frac{\sqrt{P r}}{[(N u-1) R a]^{\frac{1}{4}}}
$$

It approximately gives 0.0188 for $R a=6.3 \times 10^{5}$. The vertical grid resolution is $\Delta y=0.0104$ in the simulation and smaller than the above estimation. Note that no grid stretching is applied, and the domain interiors are resolved by the same fine resolution in the vertical direction. In case of turbulent convection, the minimum cell size for LES can be approximately determined using

$$
\begin{aligned}
& \frac{\lambda}{H} \\
& =\frac{\sqrt{15} \sqrt{0.0027 R a^{1.04}+0.0312 R a^{0.92}}}{[(N u-1) R a]^{\frac{1}{2}}}
\end{aligned}
$$

that gives 0.1342 (Peng et al. 2006). The horizontal grid spacings $\Delta x=\Delta z=0.0625$ also satisfy the 

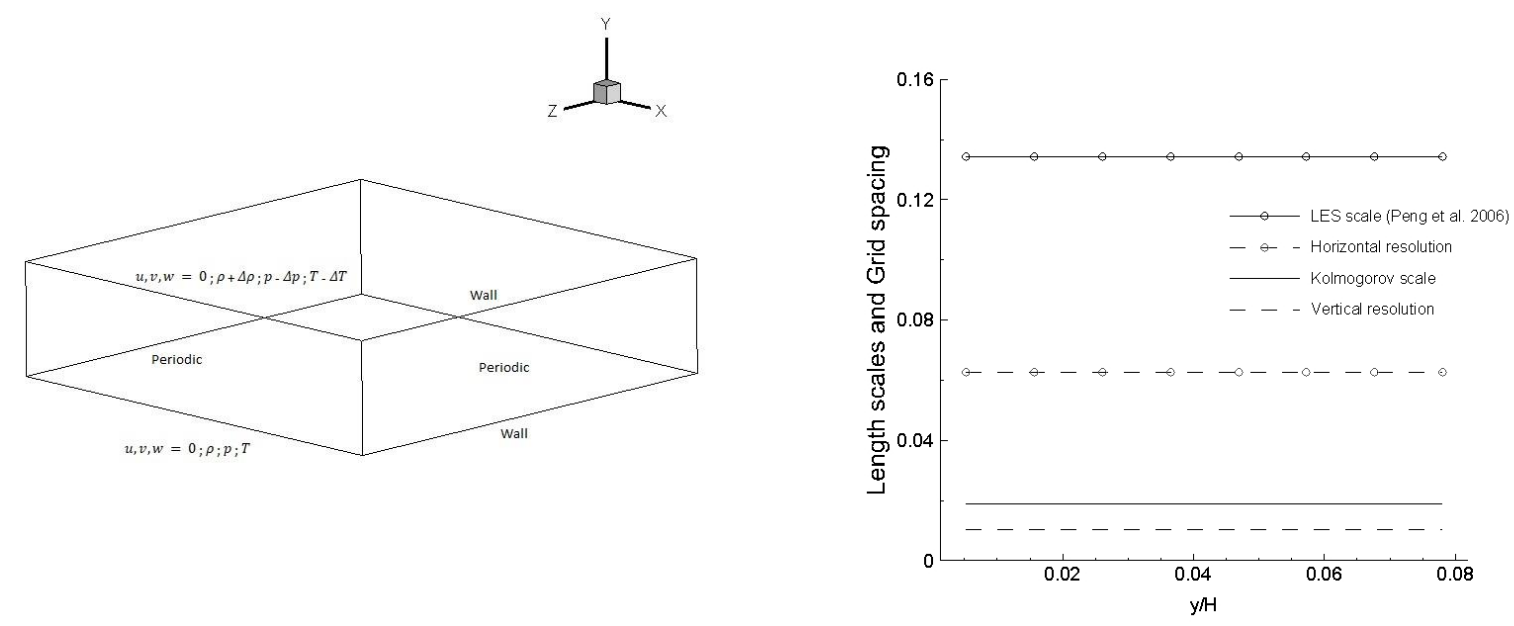

Figure 1. Schematic representation of the problem domain and boundary conditions (left), and the grid spacing in comparison with the length scales (right)
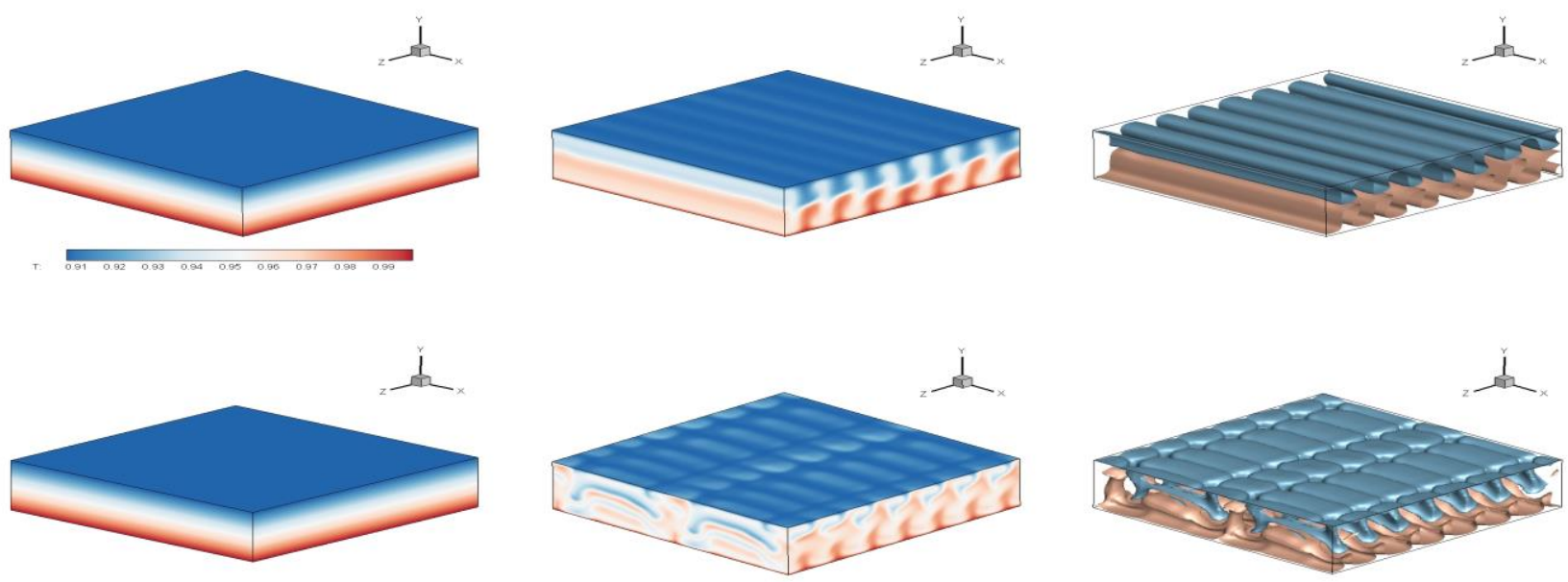

Figure 2. Initial temperature field (left), organization of flow field at very early times (middle) and corresponding hot (red) and cold (blue) iso-surfaces on default (top figures) and fine grids (bottom)

above theoretical resolution requirement. The thermal boundary layer thicknesses can be approximated as $\frac{\lambda_{\mathrm{T}}}{\mathrm{H}}=\frac{1}{2 \mathrm{Nu}}=0.0676$. At least $6-$ 7 cells are placed in the thermal boundary layers which is quite sufficient for proper resolving of thermal structures. In the above calculations, $N u=$ $0.186 R a^{0.276}$ scaling obtained by DNS was used (Kerr 1996). Evolution of the flow field was tracked up to $2100 \tau_{c}$. This is sufficiently long to obtain correct statistics which were collected at least during the last one-third period (Silano et al. 2010).

Schematic representation of the problem domain, boundary conditions, grid spacing, and length scales are given in Fig. 1. In Fig. 2, initial distribution of temperature and rapid development of wellorganized of flow structures at $84 \tau_{c}$ are provided by means of iso-surfaces.

\section{Results and Discussion}

Assessment and comparison of sgs models are made based on various mean and turbulent statistics. Fluctuating quantity of a variable is found using $\phi^{\prime}=\phi-\langle\phi\rangle$. Corresponding root mean square $(r m s)$ value is then calculated as $\phi_{r m s}=\left\langle\phi^{\prime 2}\right\rangle^{1 / 2}$ where \langle\rangle denotes the time- and space-averaging over the horizontal directions. Some 

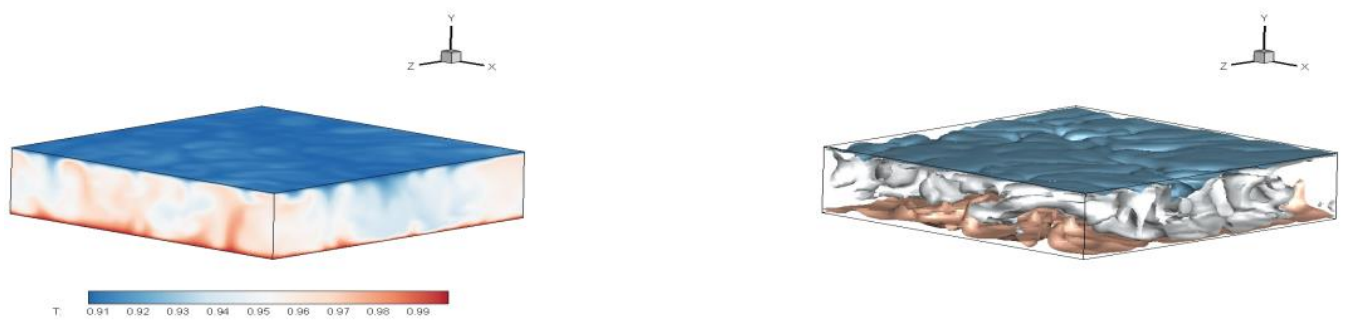

$\mathrm{i}_{x}$
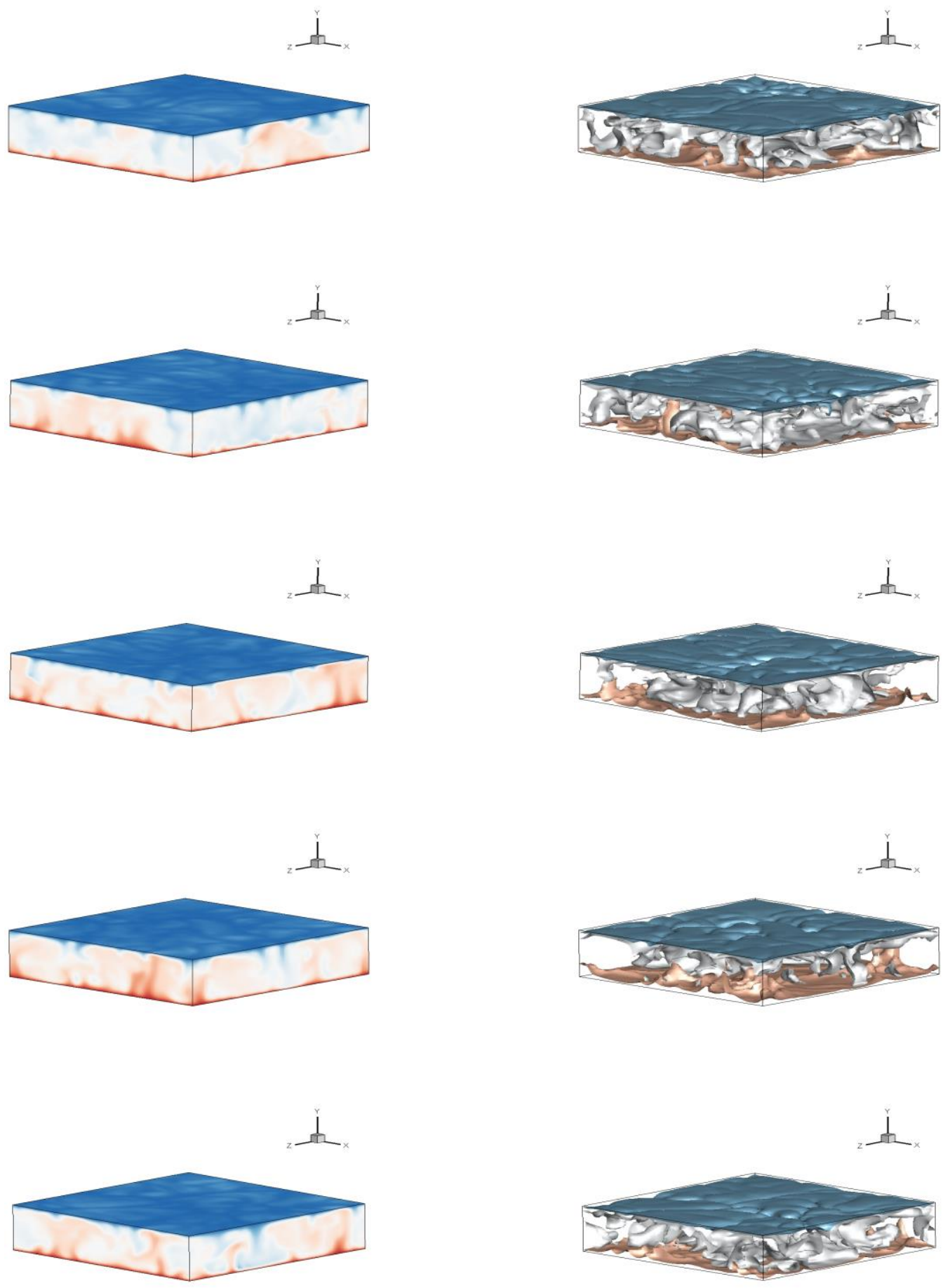

Figure 3. Instantaneous temperature fields (left column) and iso-surfaces of hot (red), cold (blue) and intermediate (gray) temperatures (right column) at time $840 \tau_{c}$. Models are SmaWD, DynSma, WALE, Vreman, MS and BM-MS from top to bottom, respectively. 
further derived diagnostics such as skewness, turbulent heat flux, sgs kinetic energy and Nusselt number $(\mathrm{Nu})$ are also computed. DNS results (where available) are provided as reference for comparison and evaluation.

Fig. 3 shows and compares the instantaneous temperature fields and corresponding iso-surfaces by means of three specified values. Initially wellorganized large-scale coherent flow structures cannot sustain themselves and rapidly evolve into a chaotic state due to strong thermal motions. Complex and challenging physics of RBC characterized by strong thermal upward and downward motions and large-scale coherent structures are qualitatively well-captured by all models. Since instantaneous snapshots were taken at a specified time, each model gives different intensities. This is also a sign that models have some quantitative differences in their predictions which will be detailed in the following analysis.

Fig. 4 shows variation of the mean resolved temperature and diffusive flux along the normalwise direction. Large portion of the domain is characterized by a single mean temperature value. As approaching walls, it starts to deviate from mean and converges the wall temperature. In general, this distribution is well-predicted by the models without any noticeable difference, except ignorable small differences observed only near walls. The diffusive flux is represented by large

gradients away from the bulk, as expected. Although overall predictions are close to each other, sgs models employing kinetic energy of the resolved fluctuations at a secondary cut-off filter (ie., MS and BM-MS) capture the wall effect earlier than the others and give a rapid response.

The normal-wise distribution of rms of temperature and vertical velocity fluctuations are plotted in Fig. 5. $T_{r m s}$ is characterized by near-wall peaks which are regarded as thermal boundary layers and a large sink at the center where thermal fluctuations are weakened, and temperature field is relatively more isotropic. This structure is sufficiently well-captured by the models. The newly
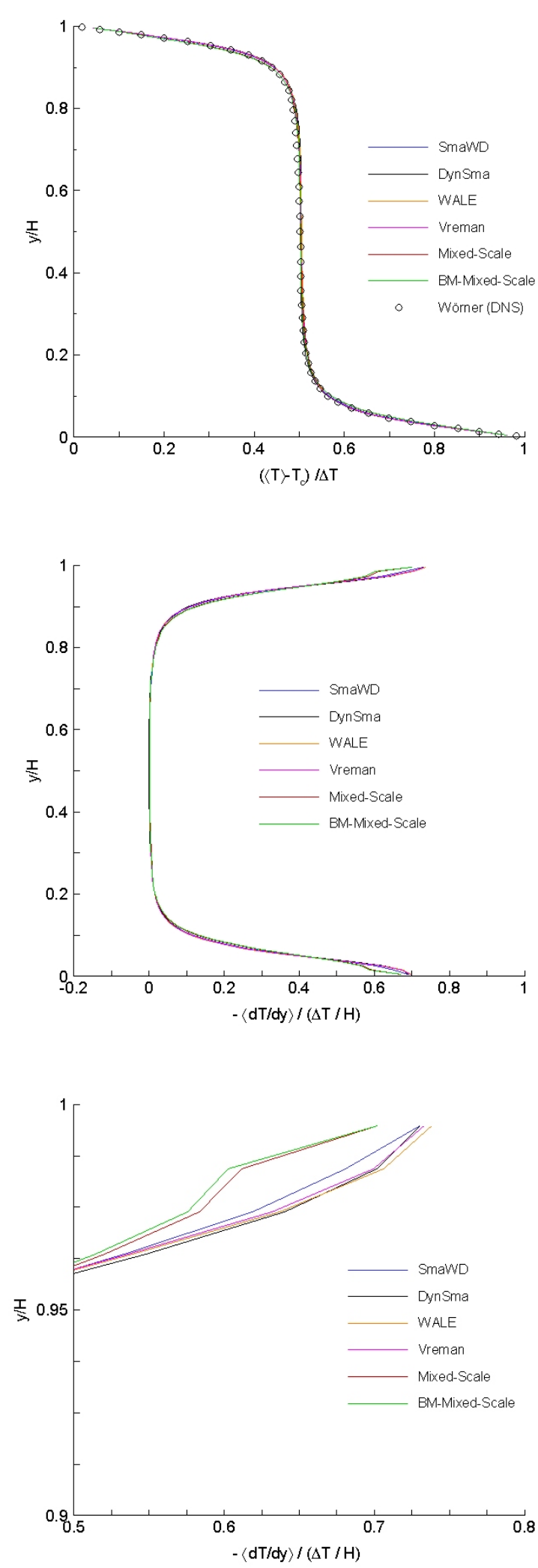

Figure 4. Normal-wise distributions of the resolved mean temperatures (top) and corresponding gradients (ie., diffusive fluxes) along vertical direction (middle) in comparison with the reference DNS (Wörner 1994). A close-up view for diffusive fluxes is also given (bottom) 

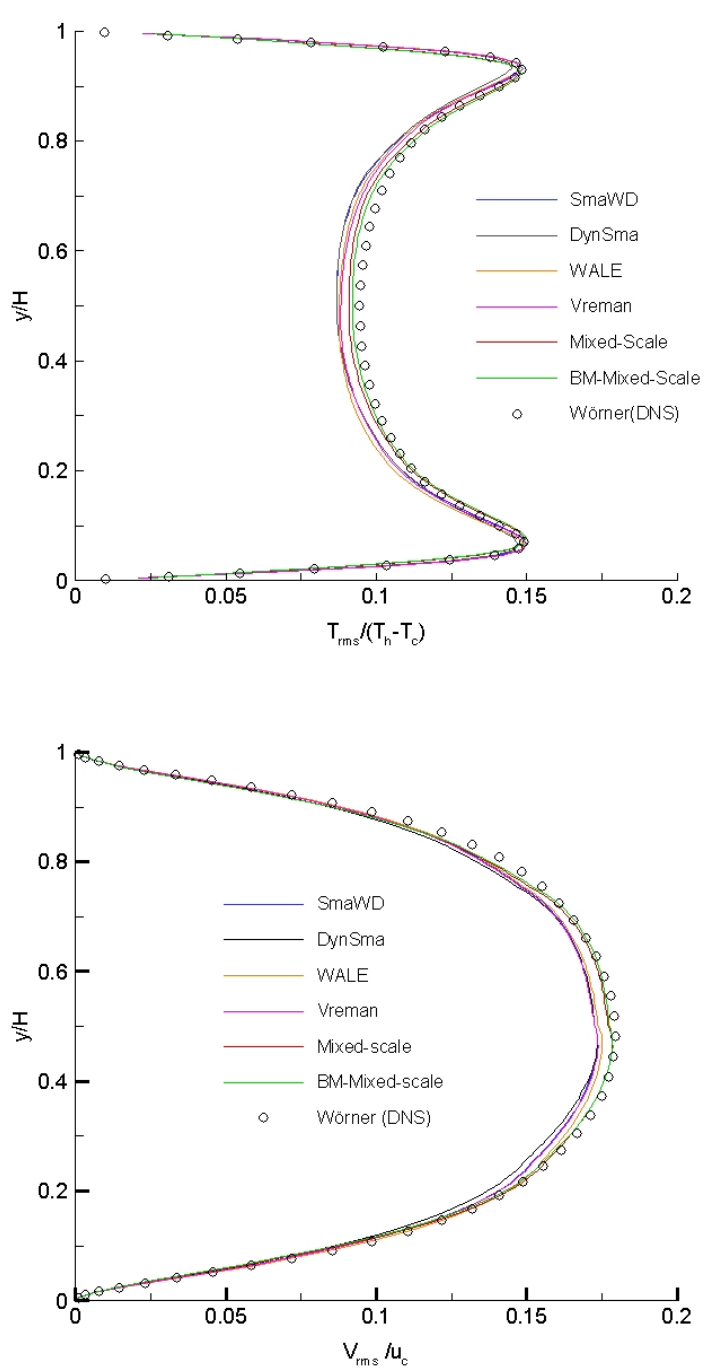

Figure 5. Normal-wise distributions of the normalized rms of temperatures (top) and vertical velocity fluctuations (bottom) in comparison with the reference DNS (Wörner 1994).

proposed BM-MS gives the closest solution to DNS, which points out an improvement over MS.

However, both models predict slightly thicker thermal boundary layers. A closer look shows that the best estimation for the peak value and its location near hot wall is given by WALE, and near cold wall, by SmaWD. DynSma unexpectedly fails to predict the peak values. However, peak location estimations are acceptable. Inside thermal boundary layers (from peaks to the walls) where large thermal gradients exist, sgs models closely follow DNS solution. $v_{r m s}$ is another important low-order turbulent statistic. Accumulation around center indicates strong and intense interactions between hot updrafts and cold downdrafts. Similar to $T_{r m s}$, this behavior is also recognized by all models. MS and its new buoyancy-modified variant BM-MS positively separate from the others and give results closer to DNS. In fact, an improvement is obtained by BM-MS. Its result is in better agreement with DNS. A closer inspection shows that Vreman and DynSma estimate the lowest velocity fluctuations, especially in the core region.

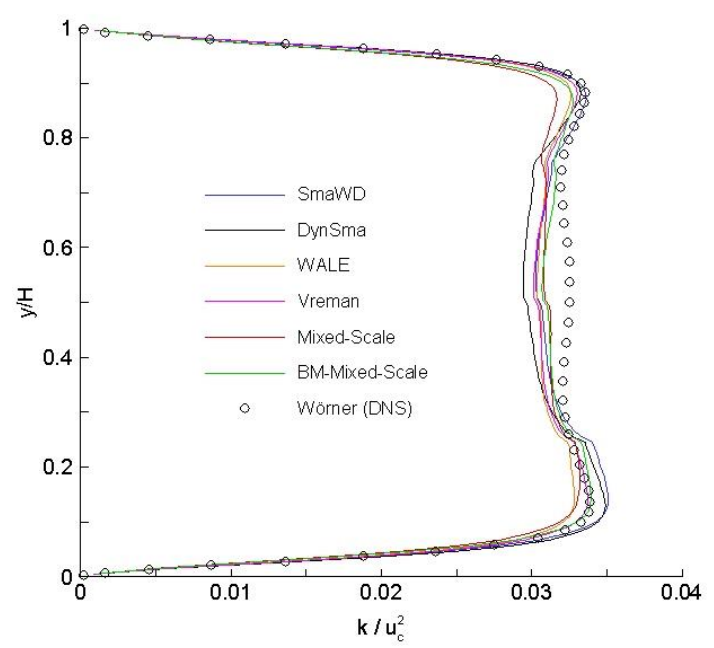

Figure 6. Normal-wise distributions of the sgs kinetic energy in comparison with the reference DNS (Wörner 1994).

The sgs kinetic energy can be computed as $k=$ $\frac{1}{2}\left(u_{h r m s}^{2}+v_{r m s}^{2}\right) \cdot u_{h r m s}$ is the rms of the combined horizontal velocity calculated as $u_{h r m s}=$ $\sqrt{u_{r m s}^{2}+w_{r m s}^{2}}$ where $w_{r m s}$ is the rms of the spanwise velocity component. $k$ is plotted in Fig. 6. At the center of the domain, all models fail. Rather than being a weakness (since it is observed in all models), this situation can be associated to relatively low grid resolution in horizontal directions compared to DNS. A similar observation was made by Peng et al. (2006). It is obvious from the equation of $k$ above, not sufficient contribution comes from the streamwise and span-wise velocity rms values. However, near wall region $k$ distribution is sufficiently captured. A detailed look shows that SmaWD and DynSma have largely asymmetric behavior near hot and cold walls. They slightly over-estimate $k$ near 
hot (bottom) wall. WALE shows a symmetric behavior. However, it slightly under-estimates $k$ near walls. Vreman agrees well with DNS away from center. MS has also asymmetric distribution and slightly under-estimates $k$ near cold (top) wall. BMMS agrees with DNS (except bulk) with a sink lower (better) than that of Vreman. This result also indicates an improvement provided by the buoyancy enhancement.

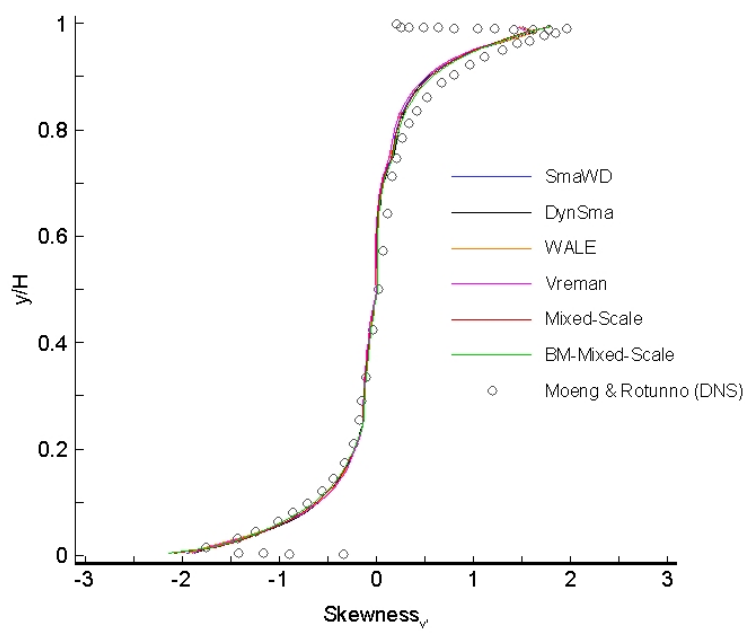

Figure 7. Distributions of skewness in comparison with the ref. DNS (Moeng and Rotunno 1990).

Skewness which is given in Fig. 7 is a high-order turbulent diagnostic derived based on verticalvelocity fluctuations via

$$
S_{v^{\prime}}=\left\langle{v^{\prime}}^{3}\right\rangle /\left\langle{v^{\prime}}^{2}\right\rangle^{\frac{3}{2}}
$$

It is characterized by a local maximum and minimum near top (cold) and bottom (hot) walls. Positive skewness corresponds to regions dominated by cold and slowly moving downward plumes that surround hot and fast upward plumes. There is a balance in the strength of vertical velocity fluctuations around the center, described by zero skewness. However, the physics of the flow is reversed as approaching the bottom wall. All sgs models are able to correctly describe the above-mentioned flow physics and in agreement with DNS. There is no noticeable difference among them. Ignorable small deviations near cold wall are observed in all models.
Turbulent heat flux distribution in Fig. 8 is best estimated by DynSma. One more time, sgs models based on MS show different character and predict larger values.

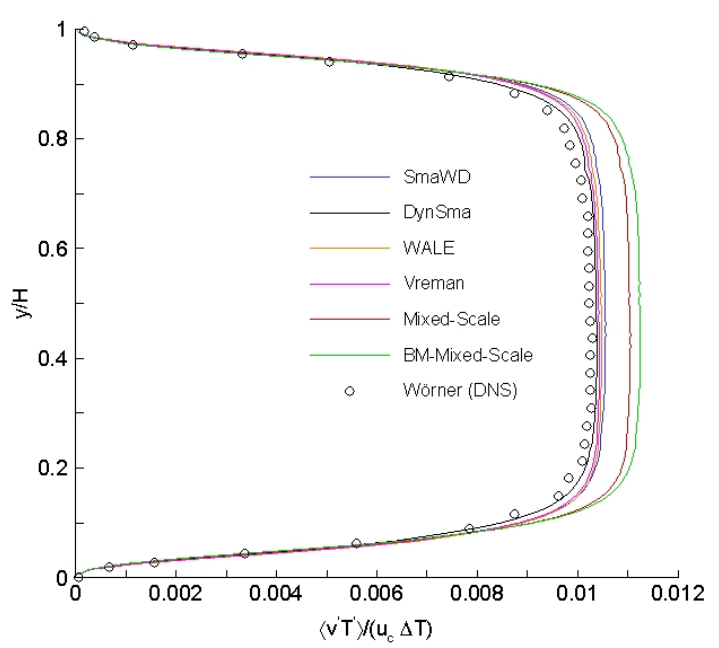

Figure 8. Normal-wise distributions of the turbulent heat fluxes in comparison with the reference DNS (Wörner 1994).

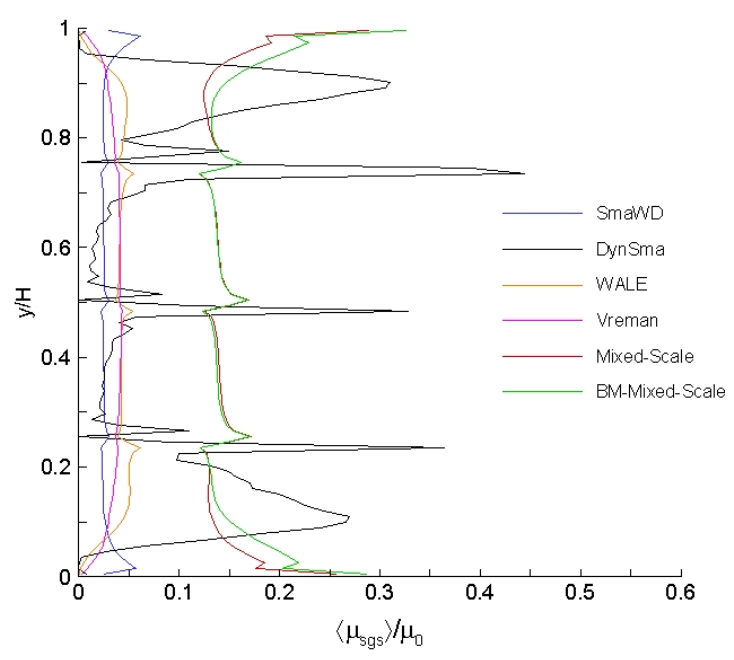

Figure 9. Normal-wise distributions of the sgs levels

Time and space-averaged sgs levels are presented and compared in Fig. 9. MS and its buoyancymodified variant have the largest predictions which are approximately three times larger than the others. The effect of enhancement by $q$ is observed here. Also, they are seperated from the others by increasingly larger sgs levels near walls. Vreman gives the straightest distribution. The differential operator that Vreman uses to compute $\mu_{s g s}$ is 

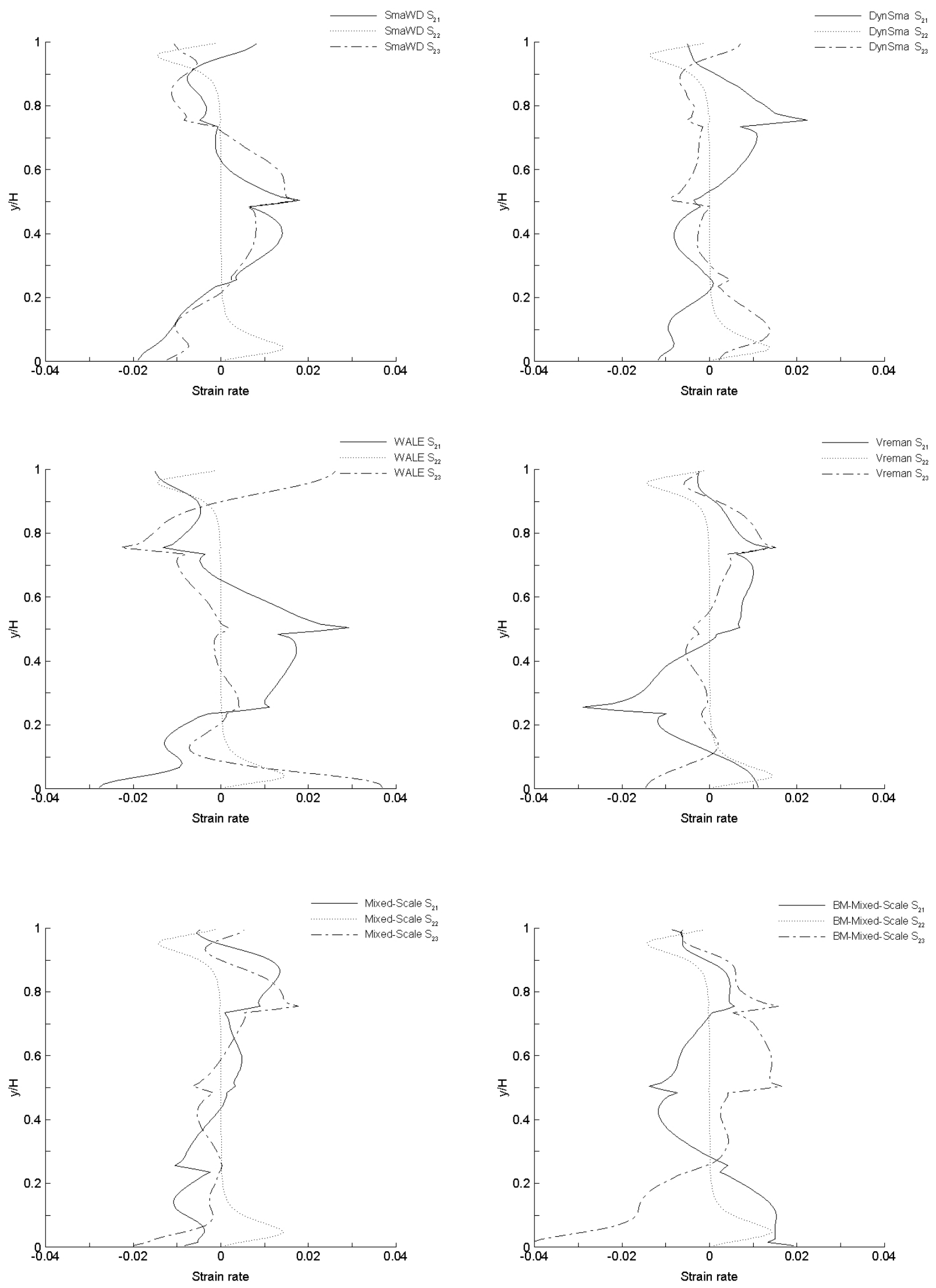

Figure 10. Normal-wise distributions of the resolved strain rate components for each sgs model 
structurally the most different one among the constant coefficient models and does not directly rely on the strain rate tensor to which the other models are somehow related. Unlike Vreman, DynSma is described by strong fluctuations. This shows that dynamic computation of $\mu_{s g s}$ is quite sensitive to local variations and gives rise an oscillatory behavior. WALE and SmaWD have similar structural behaviors.

To gain a deeper insight, components of the strain rate tensor are also computed for each model and given in Fig. 10 The results reveal that $S_{22}$ 's are nearly identical in all models and the crosscomponents $S_{21}$ and $S_{23}$ are primarily responsible for the jumps. Also, for the constant coefficient models, when $S_{21}$ and $S_{23}$ patterns are coherent, models give straighter $\mu_{s g s}$ distribution. In case of large discrepancies, strength of fluctuations increases.

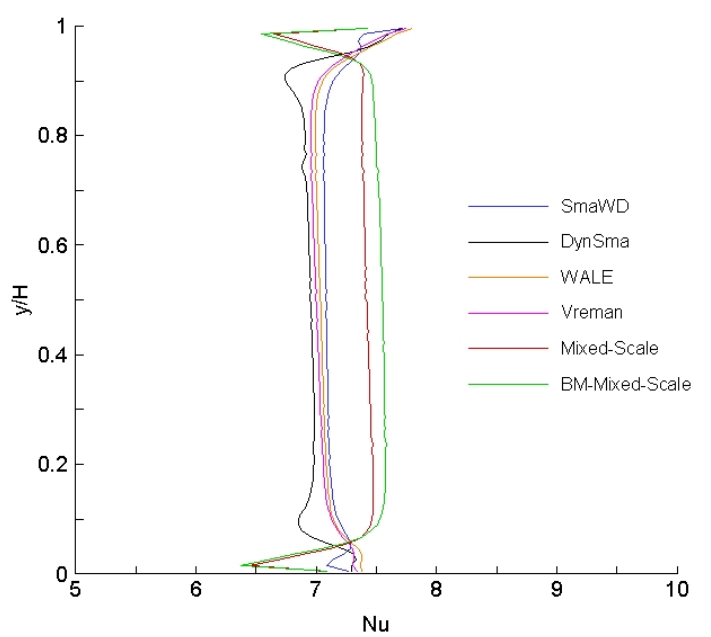

Figure 11. Normal-wise distributions of the $\mathrm{Nu}$

Fig. 11 plots the $\mathrm{Nu}$ in the normal-wise direction which is computed as

$$
N u(y)=\frac{<v^{\prime} T^{\prime}>-<\kappa \partial \tilde{T} / \partial y>}{\kappa \Delta T / H}
$$

It gives the relative strength of heat transfer mechanisms. In the bulk, Nu distribution is straight. Approaching the walls, effect of the strong temperature gradients can be observed. MS and BM-MS have larger predictions consistently with turbulent heat and diffusive fluxes. These two models have also symmetric character near walls. However, others present asymmetric distribution. SmaWD has also additional, secondary jumps. DynSma's pattern is noticeably different. It is overly sensitive to the local changes on the edge of thermal boundary layers. This may be associated to its locally dynamic coefficient feature.

Table 1. The integrated $\mathrm{Nu}$

\begin{tabular}{cl}
\hline SGS model & $\boldsymbol{N u}$ \\
\hline SmaWD & 7.12 \\
DynSma & 6.98 \\
WALE & 7.09 \\
Vreman & 7.06 \\
MS & 7.37 \\
BM-MS & 7.46 \\
DNS, Kerr (1996) & 7.41 \\
\hline
\end{tabular}

The normal-wise distribution of $\mathrm{Nu}$ can also be integrated using the trapezoidal rule to give a single representative value. Table 1 lists the values obtained by the models in comparison with wellresolved DNS (Kerr 1996). MS and BM-MS give the best estimations.

Table 2. Wall-clock times normalized by the simulation time without using a model

\begin{tabular}{cc}
\hline SGS model & Simulation Time \\
\hline SmaWD & 0.93 \\
DynSma & 1.17 \\
WALE & 0.98 \\
Vreman & 1.04 \\
MS & 0.87 \\
BM-MS & 0.87 \\
\hline
\end{tabular}

Comparison of the computational cost by means of simulation times is given in Table 2. Results are normalized by "No Model" wall-clock time on the same grid resolution. As expected, DynSma is the most expensive model computationally. The fastest models are MS-based models. Computational gain is quite satisfactory.

To reveal the whole character of the newly proposed BM-MS sgs model, a grid dependence study was also conducted on a fine grid. For this 

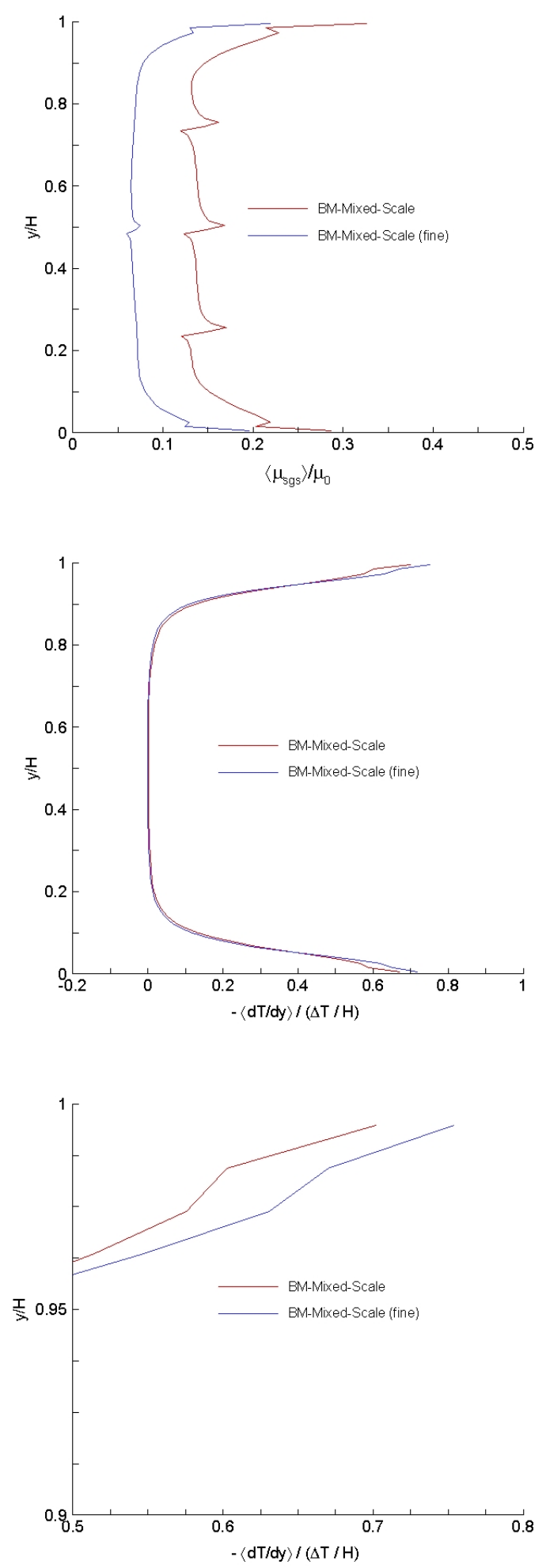

Figure 12. Turbulent statistics improved on fine grid; sgs viscosity (top), diff. heat flux (middle) and its close-up view near walls (bottom)

purpose, the grid was horizontally refined. The resolution is now $96^{3}$.

It was found that the new model is sensitive to grid resolution. While some statistics such as sgs viscosity in bulk and diffusive heat flux near walls in Fig. 12 were improved, most of the others presented in Fig. 13 were amplified and overpredicted by a level (except $\mathrm{T}_{\text {rms }}$ ). The average temperature and skewness given in Fig. 14 showed no dependence. It seems that two mechanisms on fine resolutions are determinative, ie., capturing more fluctuations and accumulation of errors. They affect and shape the overall response. Although a robust model should not significantly depend on resolution, it is known that many models inevitably suffer from the above factors. This situation is not particular to BM-MS.

Grid dependence study reveals that the proposed sgs model can produce results comparable to DNS, if grid is generated carefully to avoid the common pitfalls mentioned above. Additionally, $P r_{s g s}$ approaching to unity can also be used as an efficient fine-tuning parameter.

\section{Conclusions}

An investigation on the behavior of sgs models for LES modeling of turbulent natural convection was performed in this study. The results were also compared with each other and reference DNS solutions. The RBC problem was selected for this purpose. $\mathrm{RBC}$ is driven by strong motions of thermal plumes and characterized by large scale coherent rotational structures and secondary interactions.

It rapidly undergoes transition to turbulence over time. From the numerical perspective, this scenario is very challenging and serves as a solid test bed.

The selected models were algebraic eddy viscosity models. There are differences in the turbulent generation terms. SmaWD uses the strain rate tensor. WALE is based on an improved form of it. Vreman's term has a unique combination of crossderivatives of velocity. MS has a form enhanced by the resolved fluctuations. MS is further enhanced by buoyancy turbulent generation. To the author's best knowledge, this modification is proposed for the first time in the literature. DynSma, unlike the others, uses a dynamic coefficient to capture the 

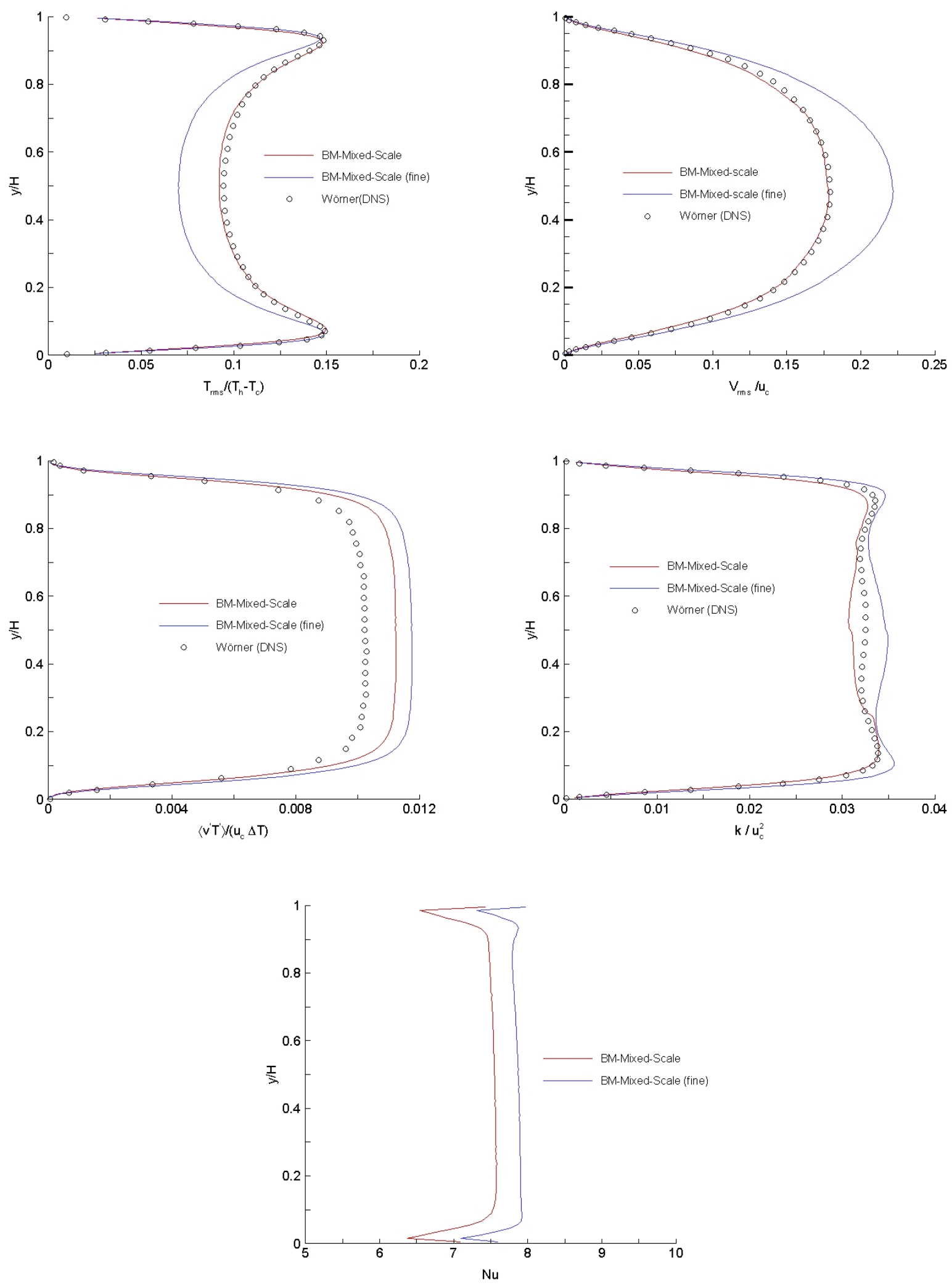

Figure 13. Turbulent statistics showed dependence on grid resolution; rms of temperature (top-left) and vertical velocity fluctuations (top-right), turbulent heat flux (middle-left), turbulent kinetic energy (middle-right), and vertical distribution of $\mathrm{Nu}$ (bottom) 

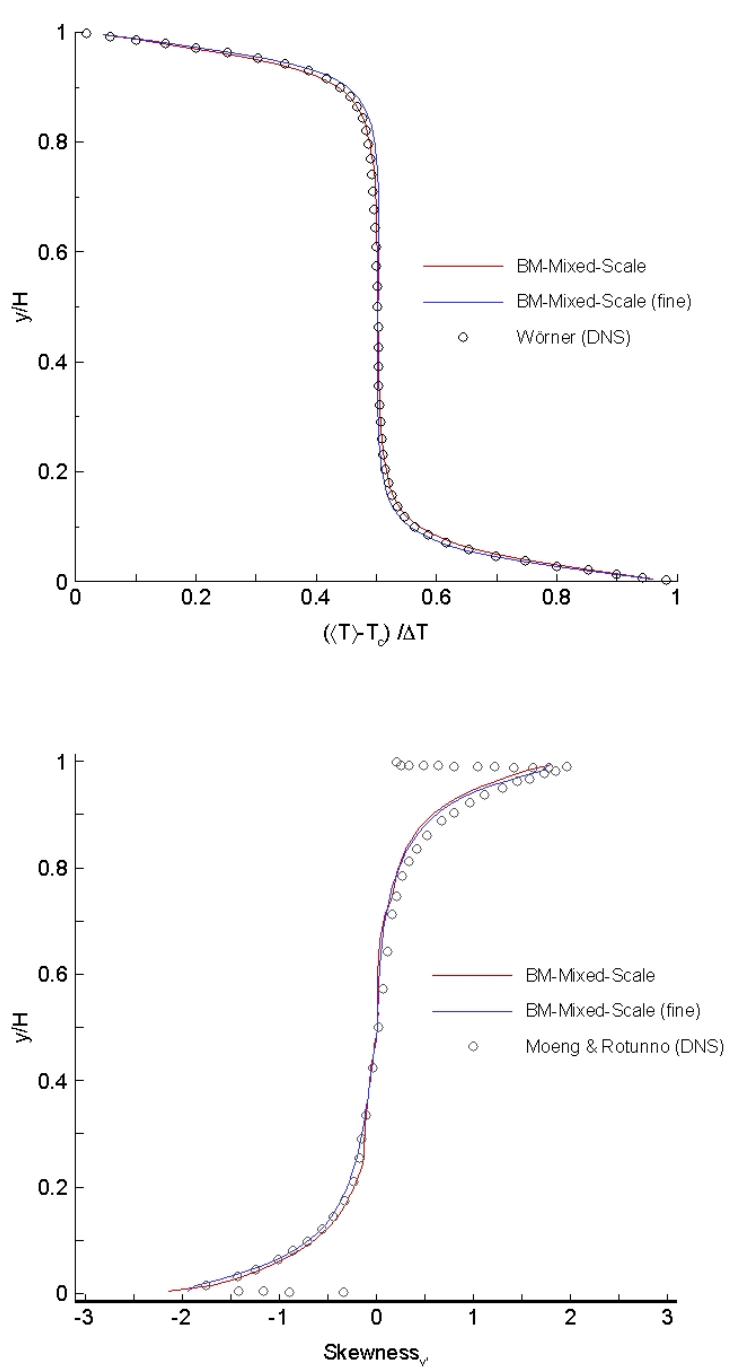

Figure 14. Turbulent statistics showed no dependence on grid resolution; average temperature (top) and skewness (bottom)

local effects. All the models were implemented into an in-house solver based on a recently proposed, advanced and efficient LES algorithm detailed above.

From the results obtained, the following conclusions can be drawn. Although all the models were overall able to reproduce the complex physics and evolution of RBC, various low- and high-order turbulent diagnostics and derived quantities computed have revealed some important differences among the models.

MS-based ones have treated the large temperature gradients (ie., resolved diffusive flux) near walls in a different way which improves the calculation of $\mathrm{Nu}$.
They were also good at estimating the first-order turbulent statistics such as $V_{r m s}$ and $T_{r m s}$. Moreover, newly proposed buoyancy-modifient variant, BM-MS has predicted slightly better. As another advantage, they are numerically inexpensive.

All models were strongly affected by the grid resolution (which was relatively lower than that of DNS) and failed in predicting sgs kinetic energy in the bulk region. However, near-walls were well resolved, and sufficient results were produced by the models.

The derived quantity based on the high-order velocity moments, skewness, was equally wellcaptured.

Models, other than the ones based on MS, have performed well in predicting turbulent heat flux in comparison with DNS.

An asymmetric behavior was shown near walls for thermal diagnostics. It was characterized by the differences in peak values and locations. This indicates that model's predictions on the thermal boundary layer properties have some differences. Some complex patterns, described by fluctuations ranging low to moderate, were observed for the $\mu_{s g s}$ level estimations. DynSma had the largest ones, while Vreman did not have any. Additionally, MS-based models estimated larger sgs levels. Improved $\mathrm{Nu}$ predictions were also made by the same models, when compared to DNS.

An additional grid dependence study for the proposed BM-MS sgs model was also performed. It was found that the model showed moderate dependence on resolution. However, on a wellbalanced grid, it is capable of predicting the mean and turbulent quantities correctly.

It is known that at high $R a$ numbers the physics of RBC considerably changes, and more complex flow features are observed. Considering this fact, further analysis may be required to reveal complete 
behavior and full potential of the models for problems with strong thermal convection.

\section{References}

Balay, S., W. D. Gropp, L. C. Mclnnes, and B. F. Smith., 1997. Efficient Management of Parallelism in Object-Oriented Numerical Software Libraries. Modern Software Tools for Scientific Computing, edited by E Arge, A. M. Bruaset, and H. P. Langtangen, Birkhäuser, 163202.

Chung, D., and G. Matheou., 2014. Large-Eddy Simulation of Stratified Turbulence. Part I: A Vortex-Based Subgrid-Scale Model. Journal of the Atmospheric Sciences 71 (5), 1863-79.

Dabbagh, F., F. X. Trias, A. Gorobets, and A. Oliva., 2016. "New Subgrid-Scale Models for LargeEddy Simulation of Rayleigh-Bénard Convection. Journal of Physics: Conference Series 745, 032041.

Eidson, T. M., 1985. Numerical Simulation of the Turbulent Rayleigh-Bénard Problem Using Subgrid Modelling. Journal of Fluid Mechanics 158, 245-68.

Getling, A. V. 1998. Rayleigh-Bénard Convection: Structures and Dynamics. Vol. 11, World Scientific, 9-26.

Gray, D. D., and A. Giorgini., 1976. The Validity of the Boussinesq Approximation for Liquids and Gases. International Journal of Heat and Mass Transfer 19 (5), 545-51.

Hou, Y., and K. Mahesh., 2005. A Robust, Colocated, Implicit Algorithm for Direct Numerical Simulation of Compressible, Turbulent Flows. Journal of Computational Physics 205 (1), 20521.
Kerr, R. M., 1996. Rayleigh Number Scaling in Numerical Convection. Journal of Fluid Mechanics 310, 139-79.

Moeng, C.-H. and Rotunno, R., 1990. Verticalvelocity skewness in the buoyancy-driven boundary layer. Journal of Atmospheric Science. 47, 1149-62.

Nicoud, F., and F. Ducros., 1999. Subgrid-Scale Stress Modelling Based on the Square of the Velocity Gradient Tensor. Flow, Turbulence and Combustion 62(3), 183-200.

Peng, S.-H., and L. Davidson., 1998. Comparison of Subgrid-Scale Models in LES for Turbulent Convection Flow with Heat Transfer. 2nd EF Conference in Turbulent Heat Transfer 1, 5.245.35

Peng, S.-H., K. Hanjalic, and L. Davidson., 2006. Large-Eddy Simulation and Deduced Scaling Analysis of Rayleigh-Bénard Convection up to Ra $=10^{9}$. Journal of Turbulence 7: N66.

Pope, S. B., 2000. Turbulent Flows. Cambridge University Press, 182-263.

Ranjan, R., M. K. Venkataswamy, and S. Menon., 2020. Dynamic One-Equation-Based Subgrid Model for Large-Eddy Simulation of Stratified Turbulent Flows. Physical Review Fluids 5 (6), 064601.

Sagaut, P., 1996. Simulations of Separated Flows with Subgrid Models. La Recherche Aerospatiale, 1, 51-63.

Sagaut, P., 2001. Large Eddy Simulation for Incompressible Flows: An Introduction. Springer-Verlag, 31-61.

Silano, G., K. R. Sreenivasan, and R. Verzicco., 2010. Numerical Simulations of Rayleigh-Bénard Convection for Prandtl Numbers between $10^{-1}$ 
and $10^{4}$ and Rayleigh Numbers between $10^{5}$ and $10^{9}$. Journal of Fluid Mechanics 662, 409-46.

Smagorinsky, J., 1963. General Circulation Experiments with the Primitive Equations: I. The Basic Experiment. Monthly Weather Review 91 (3), 99-164.

Vreman, A. W., 2004. An Eddy-Viscosity SubgridScale Model for Turbulent Shear Flow: Algebraic Theory and Applications. Physics of Fluids $\mathbf{1 6}$ (10), 3670-81.

Wörner, M., 1994. Direkte Simulation turbulenter Rayleigh- Benard-Konvektion in flüssigem
Natrium, PhD Thesis, Karlsruher Institut für Technologie, Karlsruhe, 222.

Yang, K.-S., and J. H. Ferziger., 1993. Large-Eddy Simulation of Turbulent Obstacle Flow Using a Dynamic Subgrid-Scale Model. AIAA Journal 31 (8), 1406-13.

Yilmaz, I., H. Saygin, and L. Davidson., 2018. Application of a Parallel Solver to the LES Modelling of Turbulent Buoyant Flows with Heat Transfer. Progress in Computational Fluid Dynamics, an International Journal 18 (2), 89107. 